Rajamani Sethuraman MD DNB, Santhanagopalan Kannan MD DNB, Indu Bala MD, Ramesh Kumar Sharma * $\mathrm{MS} \mathrm{MCH}$

\section{Anaesthesia in Poland syndrome}

Purpose: To describe the anaesthetic management of a child with Poland syndrome for $C T$ scan.

Clinical features: An eight-month-old child presented with left upper limb hypoplasia and chest wall deformity with absence of ribs on the left side for CT scan of thorax. Pulsations of the heart could be seen along with paradoxical respiration over the defect. The trachea was intubated and the lungs ventilated manually to avoid inadequate ventilation and hypoxia.

Conclusions: The unilateral absence of ribs leads to poor development of subatmospheric pressure in the thorax and paradoxical respiration, and may cause inadequate pulmonary ventilation and hypoxia. In the present case, positive pressure ventilation was chosen to maintain ventilation during the procedure.

Objectif : Décrire la prise en charge anesthésique pour une tomodensitométrie chez un enfant présentant un syndrome de Poland.

Aspects cliniques : Un enfant de 8 mois s'est présenté pour une tomodensitométrie du thorax; il présentait une hypoplasie du membre supérieur gauche ainsi qu'une déformation de la cage thoracique causée par l'absence de côtes du côté gauche. Au niveau de ce défaut thoracique on pouvait voir les battements cardiaques ainsi que des mouvements respiratoires paradoxaux. On a eu recours à l'intubation trachéale et à la ventilation pulmonaire manuelle pour éviter une ventilation inadéquate et une hypoxie.

Conclusions : L'absence unilatérale des côtes conduit à une faible capacité de produire des pressions négatives dans le thorax entraînant une respiration paradoxale avec ventilation pulmonaire inadéquate et hypoxie. Dans ce cas, on a choisi la ventilation à pression positive pour le maintien de la ventilation durant la procédure.

From the Departments of Anaesthesia \& Intensive Care and Plastic \& Reconstructive Surgery, ${ }^{*}$ Postgraduate Institute of Medical Education and Research, Chandigarh - 160012 , India.

Address correspondence to: Dr. Indu Bala MD; Phone: 91-172-541086; Fax: 91-172-540401.

Accepted for publication December 19, 1997. 


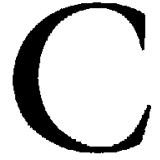

HILDREN with rare congenital anomalies may present for diagnostic or therapeutic procedures which require aniaesthesia. These patients may have either obvious external anomalies or some other associated internal anomalies which may have implications for the anaesthetist.

Poland syndrome is a rare anomaly which was first described in 1841 by Alfred Poland. The incidence varies from 1 in 30,000 to $I$ in 50,000 live births predominantly affecting males. ${ }^{1}$ It is sporadic in occurrence and occasionally familial cases are reported. ${ }^{2}$ Rarely, autosomal dominant inheritance is seen. ${ }^{3}$ Typical features of the syndrome include congenital absence of pectoralis minor and its nerve supply. ${ }^{1,4}$ The defect in the chest wall is variable with the absence or rudimentary development of anterior portion of 2 nd to 5 th ribs and their costal cartilages. As the thoracic cage grows with age, the defect also enlarges. Lung herniation can be seen during a Valsalva manoeuvre or during crying. In the Poland syndrome, the presence of a chest wall defect with no underlying bone or muscle makes this condition similar to an open chest. ${ }^{5}$ The negative pressure generated during inspiration leads to indrawing of the chest wall in the region of the defect and vice versa during expiration. The ipsilateral arm, forearm and hand are hypoplastic with syndactyly. Associated anomalies include:

1 Cardiovascular: dextrocardia, ${ }^{6}$ atrial septal defect. ${ }^{7}$

2 Musculo skeletal: contralateral syndactyly, clubfoot, toe syndactyly, hemivertebrae and scoliosis.

3 Genitourinary: renal aplasia, hypospadias and inguinal hernia.

4 Gastrointestinal: situs inversus, extension of liver through the chest.

5 Haematopoietic: spherocytosis, acute lymphoblastic $^{8}$ or myelogenous leukaemia, lymphoma.

Moebius syndrome is an extreme expression of the anomaly associated with paralysis of facial musculature, abducent and related cranial nerve palsies. ${ }^{3}$ In Parry-Romberg syndrome skin depression occurs over forehead and chin. ${ }^{10}$ This may also be associated with contralateral Poland syndrome. Another association is Adams-Oliver syndrome in which defects of skull bones and scalp, and split hand or foot can be seen.

Patients with Poland syndrome often do not have any functional disability. ${ }^{3}$ Patients can present either for diagnostic procedures like CT scan or for cosmetic surgery such as breast reconstruction.

\section{Case report}

An eight-month-old, 8-kg boy with left upper limb and chest wall deformity was referred for CT scan of the thorax. The child was born of a non-consanguineous marriage at full term. Antenatal and perinatal period had been uneventful and developmental milestones were normal. The patient was comfortable at rest and cheerful. Heart rate was $120 \mathrm{bpm}$, respiratory rate 26 per minute and room air oxygen saturation was $99 \%$ (pulse oximetry). Airway examination did not show any anticipated difficulty during intubation. The child had a bony defect of approximately $8 \times 8 \mathrm{~cm}$ over the left upper chest wall. Paradoxical respiratory movements could be seen and pulsations of the heart were visible through the defect (Figure 1). The left upper limb was hypoplastic with syndactyly and there was a restriction of movements at the elbow. No abnormality was detected on examination of the other systems.

No premedication had been given and the child was fasting for six hours. It was decided to administer general anaesthesia with controlled ventilation. Anaesthesia was induced with $5 \mathrm{mg} \cdot \mathrm{kg}^{-1}$ thiopentone after $20 \mu \mathrm{g} \cdot \mathrm{kg}^{-1}$ atropine $i v$ and tracheal intubation with a $4 \mathrm{~mm}$ uncuffed polyvinyl chloride (PVC) tube was facilitated with 2 $\mathrm{mg} \cdot \mathrm{kg}^{-1}$ succinylcholine. Anaesthesia was maintained with oxygen, nitrous oxide (66\%) and halothane $0.5-1 \%$. Ventilation was controlled with a Mapleson F system and $0.2 \mathrm{mg} \cdot \mathrm{kg}^{-1}$ atracurium was given for muscle relaxation. Heart rate and oxygen saturation remained stable throughout the procedure which lasted for $20 \mathrm{~min}$. Residual neuromuscular blockade was reversed with 0.05 $\mathrm{mg} \cdot \mathrm{kg}^{-1}$ neostigmine and $0.02 \mathrm{mg} \cdot \mathrm{kg}^{-1}$ atropine and the child made an uneventful recovery.

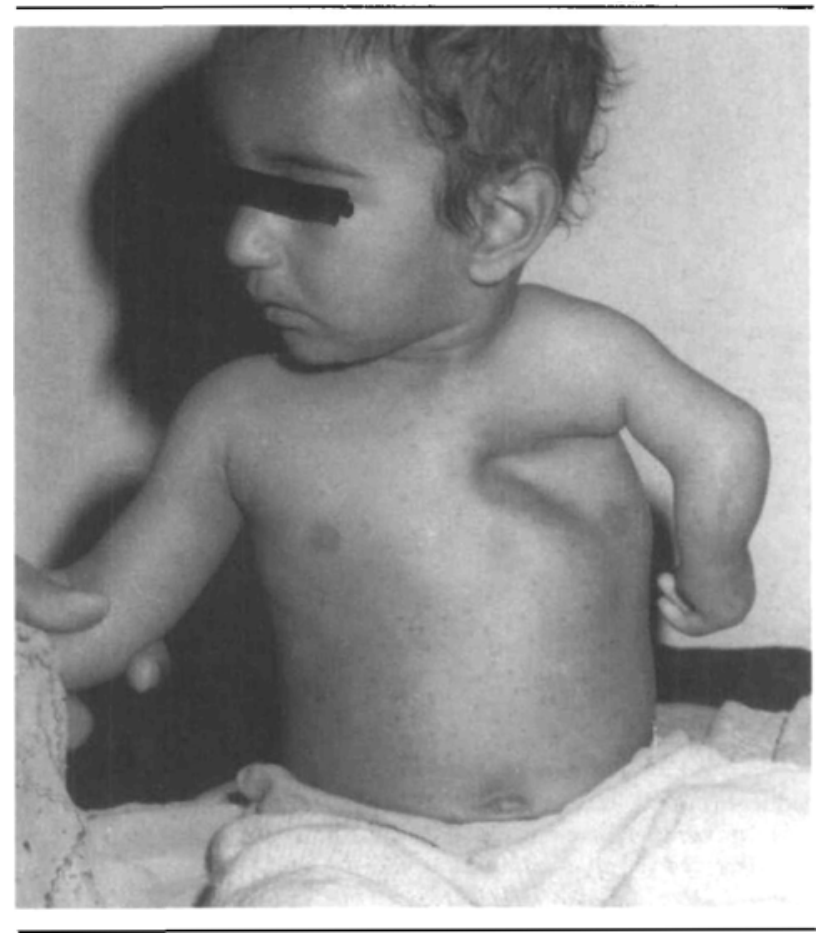

FIGURE 1 Defective anterior chest wall and hypoplastic left upper limb with webbed fingers. 


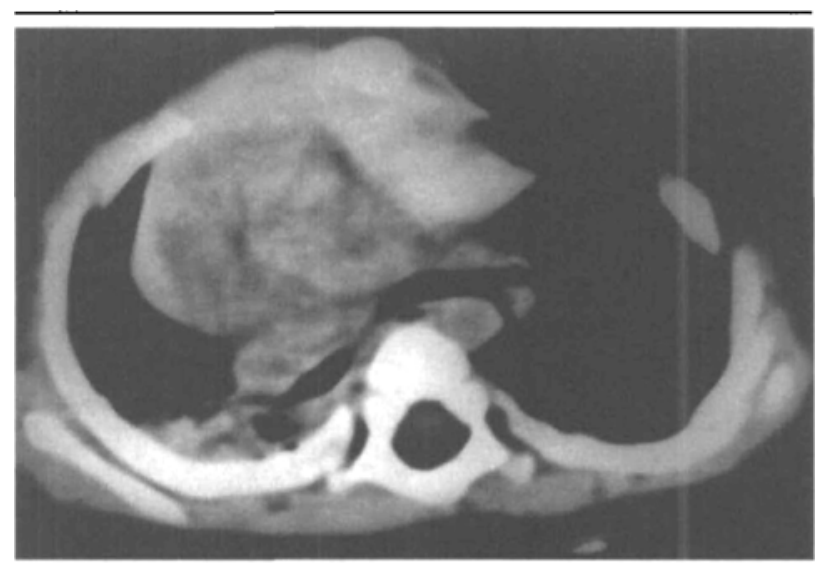

FIGURE 2 CT Scan of the thorax showing absence of ribs 2-4 on the left side.

\section{Discussion}

We report a case of Poland syndrome which presented for CT scan of the thorax. In this case only the chest wall defect was present with no associated anomalies (Figure 2). Sedation under ketamine is the usual technique in our institute for $\mathrm{CT}$ scan in children. Although this child was asymptomatic at rest it was likely that, under anaesthesia with spontaneous ventilation, the paradoxical respiratory movements would have caused inadequate ventilation. Hence, positive pressure ventilation was undertaken. The use of pulse oximeter can be valuable in these patients during the procedure.

In conclusion, the presence of chest wall defect in Poland syndrome makes it similar to an open chest and positive pressure ventilation should be used even for short procedures requiring anaesthesia.

\section{References}

1 Kevin P, David CS J $r$. Disorders of sternum and the thoracic wall. In: Sabiston DC, Spencer FC (Eds.). Surgery of the Chest, 6th ed. Philadelphia: WB Saunders, 1995: 507-11.

2 Darian VB, Argenta LC, Paryk KA. Familial Poland's syndrome. Ann Plast Surg 1989; 23: 531-7.

3 Virchel EW, Leanard M. Chapter 3. In : Rockwood CA $\mathrm{Jr}$, Masten FA III (Eds.). Congenital Anomalies of the Shoulder. Philadelphia: WB Saunders, 1990: 129-30.

4 Bainbridge LC, Wright AR, Kanthan R. Computed tomography in the preoperative assessment of Poland's syndrome. Br J Plast Surg 1991; 44: 604-7.

5 Tarban S, Moffitt EA. Principles of thoracic anesthesia. Surg Clin North Am 1973; 53: 813-26.

6 Hanka SS. Dextrocardia associated with Poland's syndrome (Letter). J Pediatr 1975; 86: 312.
7 Samant AR, Sridhar S, Desser KB, Benchimol A. Association of atrial septal defect with Poland's syndrome. Am Heart J 1983; 106: 159-61.

8 Hoefnagel D, Rozycki A, Wurster-Hill D, Stern P, Gregory $D$. Leukemia and Poland's syndrome. Lancet 1972; 2: 1038-9.

9 Bruce WH, Gustavo SM. Poland syndrome and lymphoma (Letter). Am J Dis Child 1983; 137: 1211-2.

10 Dintiman BJ, Shapiro RS, Hood AF, Guba AM. ParryRomberg syndrome in association with contralateral Poland syndrome. J Am Acad Dermatol 1990; 22: 371-3. 